\title{
Ethylic Esters as Green Solvents for the Extraction of Intracellular Polyhydroxyalkanoates Produced by Mixed Microbial Culture
}

\author{
Sara Alfano ${ }^{1}\left(\mathbb{D}\right.$, Laura Lorini ${ }^{1}$, Mauro Majone ${ }^{1}$, Fabio Sciubba ${ }^{2} \mathbb{D}$, Francesco Valentino ${ }^{3} \mathbb{D}$ \\ and Andrea Martinelli ${ }^{1, * \mathbb{D}}$
}

1 Department of Chemistry, Sapienza University of Rome, P.le Aldo Moro 5, 00185 Rome, Italy; sara.alfano@uniroma1.it (S.A.); laura.lorini@uniroma1.it (L.L.); mauro.majone@uniroma1.it (M.M.)

2 NMR-Based Metabolomics Laboratory (NMLab), Sapienza University of Rome, P.le Aldo Moro 5, 00185 Rome, Italy; fabio.sciubba@uniroma1.it

3 Department of Environmental Sciences, Informatics and Statistics, Ca Foscari University of Venice, Via Torino 155, 30170 Mestre-Venice, Italy; francesco.valentino@unive.it

* Correspondence: andrea.martinelli@uniroma1.it

check for

updates

Citation: Alfano, S.; Lorini, L.;

Majone, M.; Sciubba, F.; Valentino, F.;

Martinelli, A. Ethylic Esters as Green

Solvents for the Extraction of

Intracellular Polyhydroxyalkanoates

Produced by Mixed Microbial

Culture. Polymers 2021, 13, 2789.

https://doi.org/10.3390/

polym 13162789

Academic Editor: Matteo Minelli

Received: 21 July 2021

Accepted: 16 August 2021

Published: 19 August 2021

Publisher's Note: MDPI stays neutral with regard to jurisdictional claims in published maps and institutional affiliations.

Copyright: (c) 2021 by the authors. Licensee MDPI, Basel, Switzerland. This article is an open access article distributed under the terms and conditions of the Creative Commons Attribution (CC BY) license (https:// creativecommons.org/licenses/by/ $4.0 /)$
Abstract: Volatile fatty acids obtained from the fermentation of the organic fraction of municipal solid waste can be used as raw materials for non-toxic ethyl ester (EE) synthesis as well as feedstock for the production of polyhydroxyalkanoates (PHAs). Taking advantage of the concept of an integrated process of a bio-refinery, in the present paper, a systematic investigation on the extraction of intracellular poly(3-hydroxybutyrate-co-3-hydroxyvalerate), produced by mixed microbial culture by using EEs was reported. Among the tested EEs, ethyl acetate (EA) was the best solvent, dissolving the copolymer at the lowest temperature. Then, extraction experiments were carried out by EA at different temperatures on two biomass samples containing PHAs with different average molecular weights. The parallel characterization of the extracted and non-extracted PHAs evidenced that at the lower temperature $\left(100^{\circ} \mathrm{C}\right)$ EA solubilizes preferentially the polymer fractions richer in $3 \mathrm{HV}$ comonomers and with the lower molecular weight. By increasing the extraction temperature from $100{ }^{\circ} \mathrm{C}$ to $125^{\circ} \mathrm{C}$, an increase of recovery from about 50 to $80 \mathrm{wt} \%$ and a molecular weight reduction from $48 \%$ to $65 \%$ was observed. The results highlighted that the extracted polymer purity is always above $90 \mathrm{wt} \%$ and that it is possible to choose the proper extraction condition to maximize the recovery yield at the expense of polymer fractionation and degradation at high temperatures or use milder conditions to maintain the original properties of a polymer.

Keywords: polyhydroxyalkanoates; molecular weight; downstream processing; ethyl esters; mixed microbial culture; PHA extraction

\section{Introduction}

Stimulated by environmental concerns, the great demand for biodegradable and compostable plastic materials is partially hampered by economic reasons. In fact, although suitable alternatives to oil-based commodity polymers are available, the cost to produce bio-based polymers is higher than that of conventional plastics [1]. Polyhydroxyalkanoates (PHAs) are a class of biodegradable polyesters that can be obtained from renewable sources and, according to the composition and processing conditions, have suitable properties able to replace in some applications widespread materials, like polyethylene or polypropylene. Poly(3-hydroxybutyrate) $[\mathrm{P}(3 \mathrm{HB})]$ and its copolymers, mainly with 3-hydroxyvalerate comonomeric repeating unit $[\mathrm{P}(3 \mathrm{HB}-\mathrm{co}-3 \mathrm{HV})]$, are among the most investigated biopolymers of this class and are produced at an industrial scale [2]. The PHAs are biosynthesized as storage material by a wide range of bacteria and various consolidated strategies have been applied to maximize the accumulation of the polymer into the cells. However, the cost of the polymer is not yet competitive and, at the moment, is exploited in high added 
value applications, including biomedical devices, or when specific regulations require degradable and compostable goods. For instance, PHAs can be used in sustainable packaging applications replacing conventional petrochemical products $[3,4]$ and processed as films, fibers and foams for everyday articles such as shampoo bottles and plastic beverage bottles due to their renewability, biodegradability and high water vapor barrier [5]. Three are the main factors involved in the high PHA production cost. In order to assure a stable production and chemical composition as well as chemical-physical properties of the product, pure microbial cultures and a careful selection of the feedstock are necessary. This implies expensive sterilized conditions of fermentation reactor and substrates. The extraction and purification of the polymer from non-PHA cell mass (NPCM) is a further factor contributing to a large part of the production cost [6].

Many attempts have been investigated and experimented with to overcome these drawbacks and alternative production processes have reached the pilot plant scale [7-12]. They are mainly based on the use of mixed microbial culture (MMC) production in which the selection of microorganisms with high PHA storage capacity and biomass enrichment is obtained by aerobic dynamic feeding conditions (ADF) through the well-known feast-famine regime [13]. As a result, the use of MMC allowed to feed microorganisms with volatile fatty acid (VFA) obtained from the anaerobic fermentation of waste organic fractions of different origins rather than more expensive VFA synthetic mixtures [14,15]. Then, the MMC-based process could be a suitable cheaper alternative to the pure culture PHA production, especially taking into account that the polymers obtained from the two processes show comparable thermal and mechanical properties, mostly affecting the composition and molecular weight (MW) [16].

As far as the final downstream production process, polymer separation and recovery from the non-polymer cellular material is mainly carried out by two methods, namely disruption of NPCM through oxidation by sodium hypochlorite, hydrogen peroxide or by concentrated alkaline water solution, possibly favored by surfactants, or dissolution of PHA in an appropriate organic solvent [17].

The latter is an attractive procedure widely investigated, as evidenced by the great number of scientific papers, reviews or patents on this topic, mainly dealing with PHAs from pure culture [17-24]. In alternative to chlorinated hydrocarbons, which are the best solvents for PHAs, many research studies address the use of green solvents, with low or no toxicity and possibly derived from biochemical conversion, to overcome ecological issues, limitations involving worker safety or stringent regulations on solvent traces in goods for particular applications [25]. Solvents characterized by low toxicity, including ethers [26,27], esters [25,27-29], carbonates [29-32] and ketones [28,33,34], have been identified as appealing alternatives to chlorinated hydrocarbons. Their suitability is evaluated by taking into account their recyclability, the need for biomass pretreatment, polymer recovery yield, the quality of the extracted polymer in terms of purity and possible molecular weight reduction, as well as process cost and environmental performances [35,36].

After the extraction, the dry PHA could be obtained by low boiling point solvent distillation and recovery or by polymer precipitation by an anti-solvent. This latter operation, which could lead to an increase of the PHA purity, is mandatory if the extraction solvent has a high boiling temperature but, on the other hand, make it harder and more expensive the liquid separation and recovery.

In the present paper, taking advantage of the concept of the integrated process of a bio-refinery, the possible extraction of PHA from biomass by solubilization in ethyl esters of VFA (EEs) was investigated. The EEs, in fact, can be synthetized from the fermentation products of the organic fraction of municipal solid waste (OFMSW) and sewage sludge (SS), the same feedstock used for the production of PHA by mixed culture microorganisms [11,37]. Moreover, the selected EEs, ethyl acetate (EA), ethyl propionate (EP) and ethyl butyrate (EB), have very low toxicity. Together with butyl acetate, EA is also a suggested solvent according to all the solvent selection guides, which attribute low health and environmental scores among the whole ester class [38,39]. Nevertheless, few are 
scientific papers dealing with the use of EA for the extraction of PHA from single microbial culture and even fewer are those related to the MMC system and, to the best of authors' knowledge, no literature data are available on the use of EP and EB.

Therefore, because of the appealing possibility to use ethylic esters for the extraction of PHA from biomasses, it was considered useful to carry out a systematic analysis of the process which takes into account the effects of molecular weight of PHA in the biomass and of the extraction conditions on recovery yields, possible polymer fractionation according to PHA composition and molecular weight as well as on the properties of the non-extracted polymer remaining in the biomass. Moreover, the reported outcomes could shed some light on contradictory results reported in the literature.

Then, in this study, EEs at temperatures close or above their boiling points were used to extract PHA from two biomasses produced in a pilot plant working with MMC and a fermented mixture of OFMSW-SS as feedstock $[10,11]$. In order to investigate the influence of PHA molecular weight on the extractions, one type of biomass was stabilized by thermal treatment, which brings about an MW reduction, while the other by the addition of $\mathrm{H}_{2} \mathrm{SO}_{4}$, which has a small or null influence on MW [40]. Once EA was selected in preliminary experiments as the best solvent among EEs, the extraction with EA was carried out at different temperatures. The chemical and physical-chemical properties, including purity, composition and molecular weight of the extracted PHA as well as of the residual polymer fraction remaining in the biomass, were determined. FTIR and NMR spectroscopy were employed to investigate the cause of the polymer MW reduction observed at the highest extraction temperature.

\section{Materials and Methods}

\subsection{PHA Production}

Within the pilot platform of Treviso (northeast Italy, in the context of a full-scale municipal wastewater treatment plant), the PHA was produced from a feedstock composed of a mixture of (a) the liquid slurry coming from squeezing of the OFMSW and (b) SS from the treatment of urban wastewater. The main process setup (extensively described by Valentino et al., 2019 [10]) comprised of a first anaerobic fermentation reactor (380 L) for PHA-precursors production (volatile fatty acid, VFA), a second aerobic reactor (sequencing batch reactor, SBR; $100 \mathrm{~L}$ ) for biomass cultivation, and a third fed-batch aerobic reactor (70-90 L) for PHA accumulation within a cellular wall (40-50 wt\%). Biomass from two different batches (Biomass1 and Biomass2), with PHA content more than $50 \% w / w$ on dry weight, have been selected to perform polymer extraction and characterization. At the end of accumulation, the two biomasses were centrifuged and stabilized by two different procedures: Biomass1 was subjected to thermal treatment at $145^{\circ} \mathrm{C}$ for $30 \mathrm{~min}$ followed by overnight drying at $70{ }^{\circ} \mathrm{C}$; Biomass2 was acidified with $\mathrm{H}_{2} \mathrm{SO}_{4}$ down to $\mathrm{pH}$ 2.0. Before the extraction, Biomass 2 was washed with a $0.3 \mathrm{~N} \mathrm{NaOH}$ solution up to neutral $\mathrm{pH}$ and dried. This step was necessary to avoid polymer acidic hydrolysis by concentrated $\mathrm{H}_{2} \mathrm{SO}_{4}$.

\subsection{Preliminary Dissolution Tests}

Before the extraction experiments, the solvent properties of selected ethylic esters (EEs), were investigated by using reference PHA samples (R-PHA), obtained from the two dry biomasses by continuous chloroform Soxhlet extraction for $8 \mathrm{~h}$. This procedure brings about a nearly complete extraction of the polymer, which maintains unvaried the MW respect that of PHA inside the cells. The dissolution tests were carried out on R-PHAs by employing ethyl acetate (EA, boiling point $\left.77^{\circ} \mathrm{C}\right)$, ethyl propionate (EP, boiling point $102^{\circ} \mathrm{C}$ ) and ethyl butyrate (EB, boiling point $126^{\circ} \mathrm{C}$ ), all purchased from Sigma-Aldrich (Sigma-Aldrich, Milan, Italy). An amount of $100 \mathrm{mg}$ of dried R-PHA was placed in a $15 \mathrm{~mL}$ thick wall glass pressure vessel with PTFE bushing and Viton O-ring, magnetic stirrer and $4 \mathrm{~mL}$ of each ethylic ester. The tube was tightly closed and placed in a silicon-oil bath, preheated at the desired dissolution temperature $\left(\mathrm{T}_{\mathrm{s}}\right)$, from 100 to $150{ }^{\circ} \mathrm{C}$. It is important to take care of this procedure because high pressure could be reached into the test tube 
$\left(\mathrm{P}_{\max }=7 \mathrm{~atm}\right.$ with EA at $\left.150{ }^{\circ} \mathrm{C}\right)$. The minimum solubilization temperatures $\left(\mathrm{T}_{\mathrm{Smin}}\right)$ of R-PHAs were defined as the lowest temperature at which the solution became transparent within $1 \mathrm{~h}$. At the end of the test, each R-PHA sample was vacuum dried at $50-70{ }^{\circ} \mathrm{C}$ to a constant weight and the average viscosity molecular weight was determined. For sake of comparison, the dissolution tests were carried out also on a commercial $\mathrm{P}(3 \mathrm{HB})$ homopolymer (Biomer).

\subsection{Extraction Experiments}

The extraction capacity of the three EEs was evaluated on Biomass1. About $3 \mathrm{~g}$ of biomass and $50 \mathrm{~mL}$ of EE were inserted in a stainless-steel high pressure stirred mini reactor (Parr 4560, Moline, IL, US), preheated at $70{ }^{\circ} \mathrm{C}$. Then, the reactor was rapidly closed and heated at the extraction temperature $\mathrm{T}_{\mathrm{E}}$ equal to the minimum solubilization temperature $\mathrm{T}_{\mathrm{Smin}}$, found in the abovementioned preliminary dissolution tests. After $1 \mathrm{~h}$ under stirring, the liquid phase was withdrawn from a dip tube endowed with a stainless still mesh to avoid biomass leakage. At room temperature, the polymer precipitated forming a stable physical gel, which was vacuum dried at $50-70{ }^{\circ} \mathrm{C}$. The obtained solid (extracted PHA, E-PHA) was weighted and characterized by composition analysis and molecular weight determination.

Other than $\mathrm{T}_{\mathrm{E}}=100^{\circ} \mathrm{C}$, the extraction of PHA from Biomass 1 with EA was carried out also at increasing extraction temperatures of $115,125,135$ and $150^{\circ} \mathrm{C}$. In the experiment carried out at $\mathrm{T}_{\mathrm{E}}=125^{\circ} \mathrm{C}$, a second extraction on already extracted Biomass 1 was performed in the same conditions.

After the recovery of PHA solution in the three EEs, the biomass was vacuum dried and weighted. The residual non-extracted PHA that remained in the biomass (NE-PHA) was solubilized in chloroform by Soxhlet extraction.

The PHA weight fraction recovered by EE extraction (recovery yield, $f_{E}$ ) was evaluated by Equation (1):

$$
f_{E}=\frac{w_{s} \times p}{w_{b} \times f_{i}} \frac{V_{0}}{V_{r}} \times 100
$$

where $w_{s}$ and $p$ are the weight and purity of solid fraction in the withdrawal, $w_{b}$ is the weight of the biomass and $f_{i}$ the initial content of PHA in biomass, $V_{0}$ and $V_{r}$ are the added and recovered liquid volume, respectively. $p$ and $f_{i}$ were evaluated by the gaschromatographic method (GC).

The weight fraction $\left(f_{N E}\right)$ and the polymer composition (3HB mol\%) of non-extracted PHA were quantified by GC. The non-extracted PHA fraction $\left(f_{N E}\right)$ was calculated by taking into account the amount of polymer in non-withdrawal solvent $\left(w_{s} \times\left[V_{0}-V_{r}\right]\right)$, according to Equation (2):

$$
f_{N E}=\frac{w_{r}-w_{s} \times\left[V_{0}-V_{r}\right]}{w_{b} \times f_{i} \times V_{r}} \times 100
$$

where $w_{r}$ is the weight of non-extracted PHA. Then, the total recovered PHA is $f_{T O T}=f_{E}+f_{N E}$.

A scheme of the employed stainless-steel high pressure stirred mini reactor, original dry biomass and dried extracted PHA is reported in Figure 1.

\subsection{Characterization Methods}

The PHA content in the biomass, the purity and comonomer composition (3HB mol\%) of all the extracted samples were evaluated by the gas-chromatographic method according to Braunegg et al. [41]. Approximately $3.5 \mathrm{mg}$ of dried biomass were suspended in $2 \mathrm{~mL}$ of acidified methanol solution (at $3 \% v / v \mathrm{H}_{2} \mathrm{SO}_{4}$ ) containing benzoic acid (at $0.005 \% \mathrm{w} / v$ ) as internal standard and $1 \mathrm{~mL}$ of chloroform in a screw-capped test tube. Then, an acidcatalyzed methanolysis of the PHA occurred and the released methyl esters were quantified by gas-chromatography (GC-FID Perkin Elmer 8410). The relative abundance of $3 \mathrm{HB}$ and $3 \mathrm{HV}$ comonomers was determined using a commercial $\mathrm{P}(3 \mathrm{HB}-\mathrm{co}-3 \mathrm{HV})$ copolymer with a $3 \mathrm{HV}$ content of $5 \mathrm{wt} \%$ (Sigma-Aldrich, Milan, Italy) as a reference standard. 


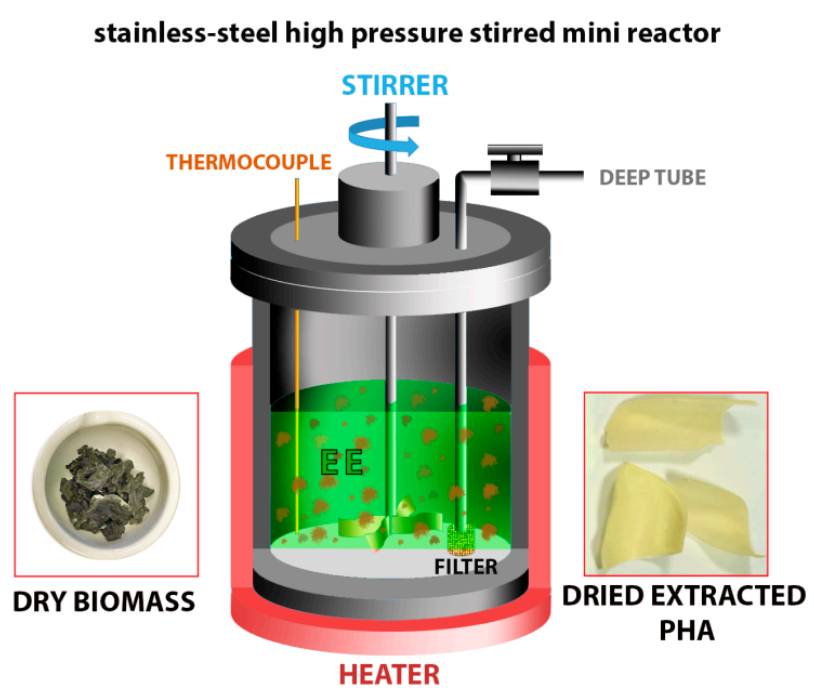

Figure 1. Scheme of the employed stainless-steel high pressure stirred mini reactor, original dry biomass and dried extracted PHA.

The viscosity average molecular weight $\left(M_{v}\right)$ of E-PHA and NE-PHA samples was determined by dilute solution viscosimetry in chloroform at $30^{\circ} \mathrm{C}$. The polymer intrinsic viscosity $([\eta])$ was related to $M_{v}$ by Mark-Houwink Equation (3):

$$
[\eta]=k \times M_{v}^{a}
$$

In actuality, the employed values of $k=7.7 \times 10^{-5}$ and $\alpha=0.82$, suggested by Marchessault et al. [42], were reported for $\mathrm{P}(3 \mathrm{HB})$ homopolymer. Nevertheless, for comparison purposes, the $M_{v}$ values of $\mathrm{P}(3 \mathrm{HB}-c o-3 \mathrm{HV})$ copolymer were given hereinafter, taking into account the nearly equal composition and the low $3 \mathrm{HV}$ content of PHAs in both biomasses.

All the extracted samples were characterized by FT-IR spectroscopy in attenuated total reflection mode (ATR) by using a Thermo Nicolet 6700 instrument (Thermo Scientific, Waltham MA, USA), equipped with a Golden Gate diamond single reflection device (Specac LTD, Orpington, UK). The spectra were collected co-adding 200 scans at a resolution of $4 \mathrm{~cm}^{-1}$ in the range $4000-650 \mathrm{~cm}^{-1}$.

The extracted samples with EA at $150^{\circ} \mathrm{C}$ were analyzed by $1 \mathrm{H}-\mathrm{NMR}$ spectroscopy by a Bruker AVANCE III spectrometer (Bruker BioSpin, Karlsruhe, Germany), equipped with a Bruker multinuclear z-gradient inverse probe-head operating at the proton frequency of $400.13 \mathrm{MHz}$. The sample was solubilized in deuterated chloroform and the $1 \mathrm{H}$ spectra were acquired at $298 \mathrm{~K}$ employing a spectral width of $15 \mathrm{ppm}(6009.13 \mathrm{~Hz}), 64 \mathrm{k}$ data points, 32 scans and a relaxation delay of $6.55 \mathrm{~s}$ in order to achieve full relaxation for all the sample protons.

The block diagram of sample transformations (red lines) and characterizations (blue lines) is reported in Figure 2.

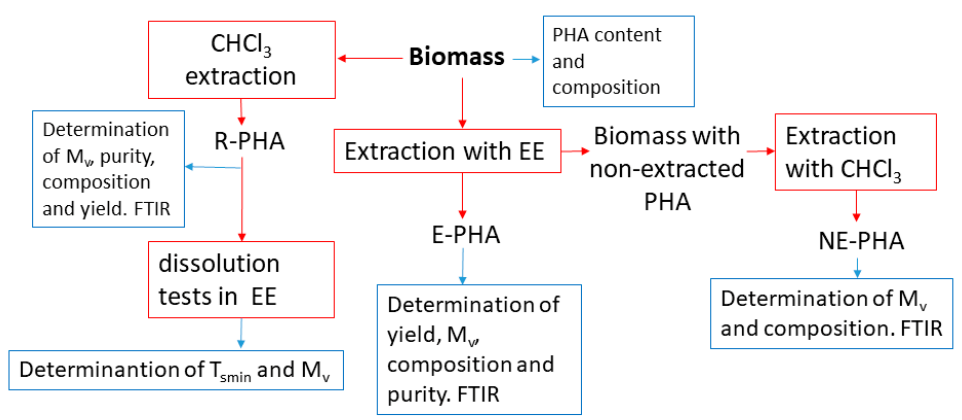

Figure 2. Block diagram of the sample transformations (red lines) and characterizations (blue lines). 


\section{Results and Discussion}

\subsection{Screening of Different EEs as PHA-Extraction Solvents}

The polymer content and composition obtained by GC analyses of the two biomasses, as well as the viscosity average molecular weight of PHAs extracted in Soxhlet by chloroform (R-PHA1 from Biomass1 and R-PHA2 from Biomass2), are reported in Table 1.

Table 1. Content, composition and viscosity average molecular weight of PHAs in the two biomasses and minimum solubilization temperature $\left(\mathrm{T}_{\mathrm{smin}}\right)$ of R-PHAs and Biomer in the tested EEs.

\begin{tabular}{|c|c|c|c|c|c|c|}
\hline Sample & $\begin{array}{c}\text { PHA Content } \\
\text { in Biomass }(w t \%)\end{array}$ & $\begin{array}{l}\text { Composition } \\
\text { (3HB mol\%) }\end{array}$ & $M_{v}\left(\mathrm{~kg} \mathrm{~mol}^{-1}\right)$ & $\begin{array}{c}\mathrm{T}_{\mathrm{smin}} \text { in } \mathrm{EA} \\
\left({ }^{\circ} \mathrm{C}\right)\end{array}$ & $\underset{\left({ }^{\circ} \mathrm{C}\right)}{\mathrm{T}_{\mathrm{smin}} \text { in } \mathrm{EP}}$ & $\underset{\left({ }^{\circ} \mathrm{C}\right)}{\mathrm{T}_{\mathrm{smin}} \text { in } \mathrm{EB}}$ \\
\hline Biomass1 & 56 & 83 & - & - & - & - \\
\hline Biomass2 & 62 & 89 & - & - & - & - \\
\hline R-PHA 1 & - & 83 & $139 \pm 3$ & 100 & 115 & 120 \\
\hline R-PHA 2 & - & 89 & $405 \pm 5$ & 115 & - & - \\
\hline BIOMER & - & 100 & $390 \pm 10$ & 115 & - & - \\
\hline
\end{tabular}

As expected, the chloroform extraction led to a high recovery yield (96 $\mathrm{wt} \%)$ and both R-PHAs showed high purity ( $98 \mathrm{wt} \%$ ) and the same composition found by GC analysis of biomasses.

PHAs in biomasses are exclusively $\mathrm{P}(3 \mathrm{HB}-\mathrm{co}-3 \mathrm{HV})$ copolymers with similar chemical compositions. The high $3 \mathrm{HB}$ monomer content was due to the fermented feedstock composition; in fact, the molar fraction of acids containing an odd number of carbon atoms (mainly propionic and valeric, precursors of HV formation) compared to total VFA was quite low and the VFA distribution was strongly oriented to the predominance of acids with even number of C-atoms (mainly acetic and butyric; $0.15-0.17 \mathrm{~mol} / \mathrm{mol}$ ) [10]. This parameter was already used to characterize VFA distribution in complex mixtures and, in turn, to predict the chemical composition of PHA.

The different $M_{v}$ of the two R-PHA samples is likely due to the different stabilization methods [43,44]. In fact, it has been previously observed how the thermal treatment, used for the stabilization of Biomass1, led to a molecular weight reduction, due to partial polymer hydrolysis favored by high temperature.

At room temperature, EEs do not solubilize the $\mathrm{P}(3 \mathrm{HB}-\mathrm{co}-3 \mathrm{HV})$ and the complete dissolution occurred at a temperature above (EA, EP) or close (EB) to the boiling points of the liquids. In Table 1 , the minimum solubilization temperature $\left(\mathrm{T}_{\mathrm{smin}}\right)$ of R-PHA1 in the tested EEs and R-PHA2 in EA are reported. For sake of comparison, $\mathrm{T}_{\mathrm{smin}}$ in EA of the commercial Biomer, a poly(3-hydroxybutyrate) homopolymer (P3HB), was also found. The dissolution tests of R-PHA1 showed that the shorter is the EE acylic residue the lower is the $\mathrm{T}_{\mathrm{smin}}$ and that the EA solubilized R-PHA2 and Biomer at a higher temperature than R-PHA1, presumably because of the higher molecular weight of these polymers.

According to the preliminary dissolution tests, the PHA extraction from Biomass1 was carried out initially with the three EEs at $T_{E}$ equal to $T_{\text {smin }}$.

After $1 \mathrm{~h}$, at the end of the extraction, the liquid phase was withdrawn from high pressure stirred mini-reactor by the dip tube at $\mathrm{T}=\mathrm{T}_{\mathrm{E}}$ to avoid physical gel formation and to favor the separation of the solution from the solid biomass. In this way, about $92-95 \mathrm{vol} \%$ of the initial solvent volume was recovered ( $V_{r}$ in Equations (1) and (2). Then, weight, purity, composition and molecular weight of dry extracted PHA fraction solubilized in EEs (E-PHA1) were measured. Moreover, the fraction $\left(f_{N E}\right)$ and composition of the nonextracted polymer (NE-PHA1) from the biomass were determined by GC. The results of the analyses are displayed in Table 2. 
Table 2. Characterization of the extracted (E-PHA1) and of the non-extracted PHA (NE-PHA1) from Biomass1 with the three EEs.

\begin{tabular}{|c|c|c|c|c|c|c|}
\hline \multirow[b]{2}{*}{ Solvent } & \multicolumn{4}{|c|}{ E-PHA1 } & \multicolumn{2}{|c|}{ NE-PHA1 } \\
\hline & $\begin{array}{c}f_{E} \\
(\mathbf{w t} \%)\end{array}$ & $\begin{array}{l}\text { Composition } \\
\text { (3HB mol\%) }\end{array}$ & $\begin{array}{l}\text { Purity } \\
(w t \%)\end{array}$ & $\begin{array}{c}M_{v} \\
\left(\mathrm{~kg} \cdot \mathrm{mol}^{-1}\right)\end{array}$ & $\begin{array}{c}f_{N E} \\
(\mathbf{w t} \%)\end{array}$ & $\begin{array}{l}\text { Composition } \\
(3 \mathrm{HB} \text { mol\%) }\end{array}$ \\
\hline EA at $100^{\circ} \mathrm{C}$ & 54 & 72 & 97 & 72 & 44 & 89 \\
\hline $\mathrm{EP}$ at $115^{\circ} \mathrm{C}$ & 45 & 74 & 100 & 38 & 52 & 88 \\
\hline EB at $120^{\circ} \mathrm{C}$ & 32 & 57 & 84 & 29 & 62 & 90 \\
\hline
\end{tabular}

Table 2 highlights that the polymer solubilized from the biomass with the different EEs, after solvent evaporation, shows a high purity and an increase of $3 \mathrm{HV}$ comonomeric unit content with respect to those of R-PHA1. Accordingly, in non-extracted NE-PHA, the $3 \mathrm{HB} \mathrm{mol} \%$ value increased. Moreover, it can be observed that all the E-PHA1s, extracted with the three EEs, are characterized by $M_{v}$ lower than that of the reference sample. Since the extraction by EA gave the best recovery yield and the lowest $M_{v}$ reduction, further investigation was carried out with this solvent.

\subsection{Evaluation of PHA Extraction Performances with Ethyl Acetate (EA)}

The $M_{v}$ and composition variation of extracted polymers reported in Table 2 could occur because of selective solubilization of polymer according to its molecular weight and composition and/or of a degradative process taking place at high temperature. Thus, the effect of the temperature on polymer molecular weight was investigated by dissolving the references samples (R-PHA1 and R-PHA2) in EA also at $105^{\circ} \mathrm{C}<\mathrm{T}_{\mathrm{s}}<150{ }^{\circ} \mathrm{C}$. After $1 \mathrm{~h}$, the polymer samples were recovered, dried and the molecular weights determined. In Figure 3, the $M_{v}$ variation as a function of solubilization temperature $\mathrm{T}_{\mathrm{s}}$ is reported. For sake of comparison, the experiment was performed also on Biomer at $115^{\circ} \mathrm{C}$ and $150{ }^{\circ} \mathrm{C}$.

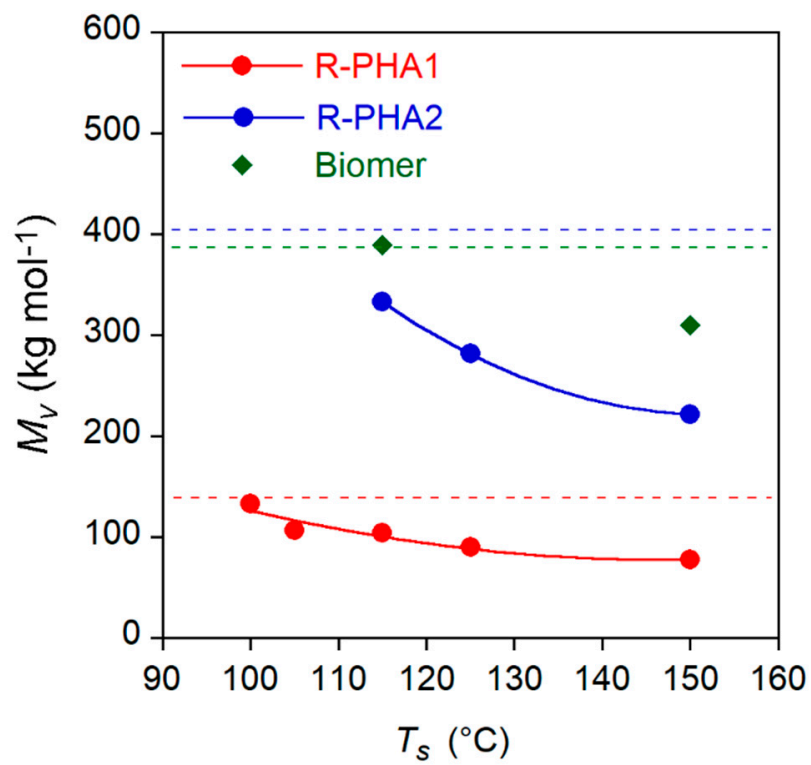

Figure 3. PHA1, R-PHA2 and Biomer viscosimetry average molecular weight $\left(M_{v}\right)$ variation as a function of the dissolution temperature in EA. Dotted lines indicate the $M_{v}$ values of R-PHAs and of pristine Biomer. Solids curves are a guide for the eyes.

Figure 3 shows that the R-PHA dissolution at an increasing temperature brought about a progressive molecular weight reduction up to $44 \%$ at $150{ }^{\circ} \mathrm{C}$ for both polymers. The homopolymer Biomer seems to be more stable towards degradation phenomena showing a $M_{v}$ decrease null at $115{ }^{\circ} \mathrm{C}$ and of $20 \%$ at $150{ }^{\circ} \mathrm{C}$. Therefore, it could be inferred that the polymer in the solution undergoes progressive degradation as the temperature increases. This phenomenon was further investigated to assess the effect of the temperature on the EA 
extraction of PHA from biomass. Further experiments were carried out by extracting PHA from Biomass1 with EA at the same temperatures of dissolution reported in Figure 3. As in the experiments conducted at $\mathrm{T}_{\mathrm{E}}$ equal to $\mathrm{T}_{\mathrm{s}}$, the E-PHA1 and NE-PHA1 fractions $\left(f_{N E}\right.$ and $f_{E}$, respectively) as well as their compositions and molecular weights were analyzed. The results are reported in Figure 4, where the molecular weight of R-PHA1 obtained in the dissolution experiments, already reported in Figure 3, is displayed for comparison. The results at $\mathrm{T}_{\mathrm{E}}=77^{\circ} \mathrm{C}$ refer to the E-PHA1 extracted in Soxhlet with EA.
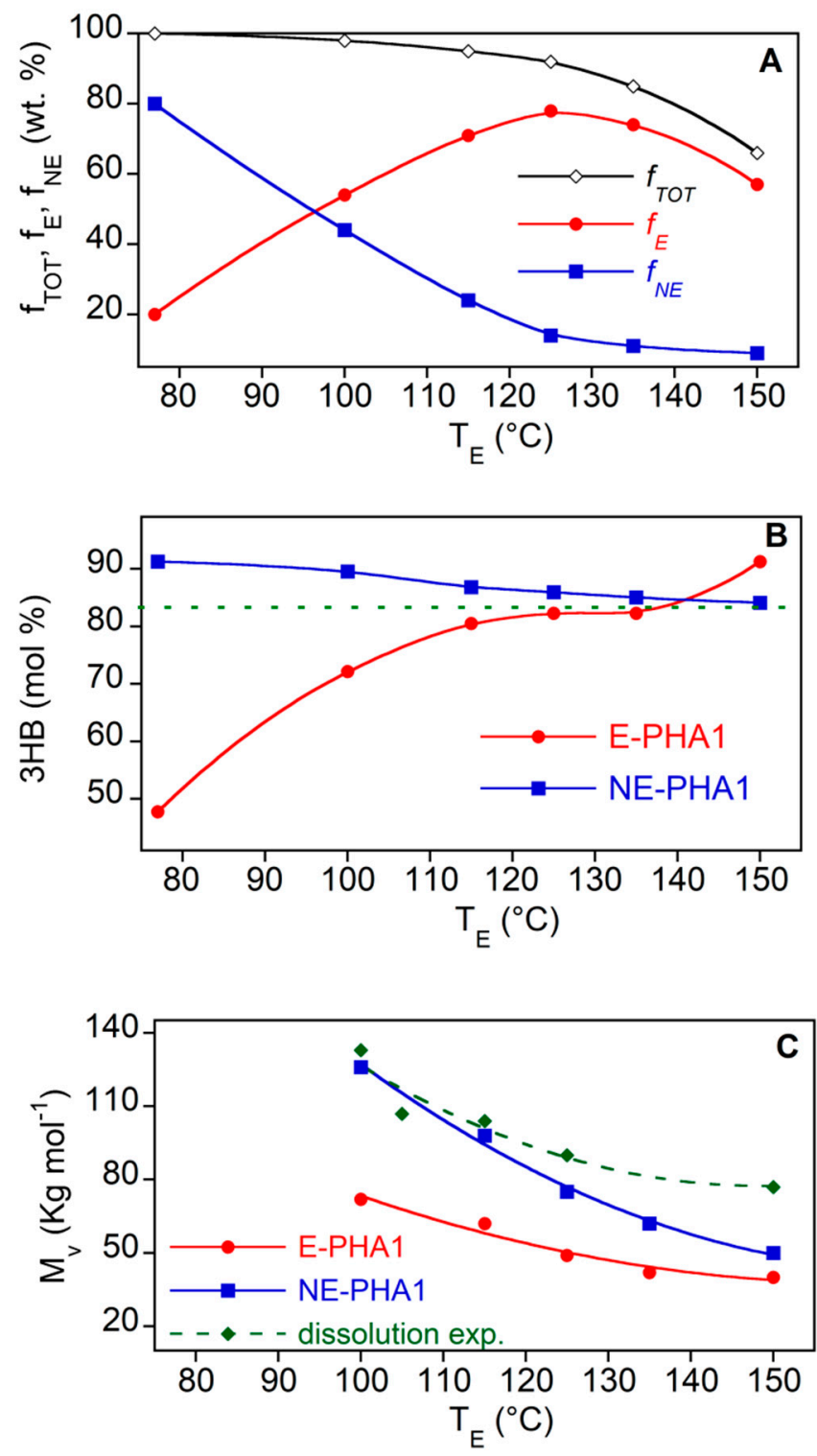

Figure 4. Total $\left(f_{T O T}\right)$, extracted $\left(f_{E}\right)$ and non-extracted $\left(f_{N E}\right)$ PHA fractions $(\mathbf{A})$, composition $(\mathbf{B})$ and average viscosimetry molecular weight (C) of E-PHA1 and NE-PHA1 as a function of extraction temperature $\mathrm{T}_{\mathrm{E}}$ with $\mathrm{EA}$. The dotted line in (B) is the composition of R-PHA1. The green diamond marks in (C) are the molecular weight of R-PHA1 after the dissolution experiments already reported in Figure 3. All the lines are guides for the eyes.

Figure 4A shows that the PHA extracted fraction $\left(f_{E}\right)$ increased by increasing temperature up to $125^{\circ} \mathrm{C}$. The decrease at higher temperatures did not reflect the expected increase of the non-extracted polymer fraction $\left(f_{N E}\right)$ remaining in the biomass, leading to a total recovery $f_{\text {TOT }}$ below $100 \mathrm{wt} \%$. Except a small amount of sample lost in the extraction and recovery procedures, this could be attributed to the formation at the highest temperatures 
of volatile degradation products, as shown later. On the other hand, the purity of the extracted and dried samples was always high, between 90 and $97 \mathrm{wt} \%$ (not reported), also without further steps of polymer precipitation with the use of an anti-solvent. Figure 4B shows that the increase of temperature reduced the preferred solubilization of the $3 \mathrm{HV}$ rich polymer fraction up to $125-130^{\circ} \mathrm{C}$, where the extracted PHA has a composition similar to that of pristine polymer in biomass. Figure $4 \mathrm{C}$ highlights that the PHA fraction solubilized in EA shows a lower $M_{v}$ than that remaining in the biomass. This lets us infer a preferred degradation of the polymer in solution or a preferred solubilization of shorter chains. Moreover, at $\mathrm{T}_{\mathrm{E}}>115^{\circ} \mathrm{C}$, the $M_{v}$ of both E-PHA1 and NE-PHA1 decreases at values lower than that of R-PHA1, heated at the same temperature (green diamond marks), evidencing an active role of the biomass on the reduction of molecular weight. This evidence could be related to the finding of Kopinke et al. [45], that, in a study on P(3HB) kept at a temperature above the polymer melting point, a decrease of the polymer thermal stability in presence of crude biomass was found. More specifically, in thermal degradation investigation on $\mathrm{P}(3 \mathrm{HB}-\mathrm{co}-3 \mathrm{HV})$, Xiang et al. [46] have suggested that calcium ions traces remaining in the copolymer may accelerate the chain scission reaction. In fact, as shown later, the reported chain scission reaction products occurring above the melting point are the same as those observed for the polymer in EA solution at high temperatures.

Ultimately, the results of PHA extraction from biomass by using EA showed that the recovery yield $f_{E}$ increases with temperature up to $125-135^{\circ} \mathrm{C}$, but at the expense of a drastic reduction of the polymer molecular weight.

A second extraction for $1 \mathrm{~h}$ further at $125^{\circ} \mathrm{C}$ of the already extracted biomass brought about a PHA recovery of about $7 \mathrm{wt} \%$. This nearly corresponds to the polymer fraction solubilized in EA but not withdrawn in the first experiment. Therefore, it can be concluded that longer extraction experiments did not lead to a significant $f_{E}$ increase.

The extraction experiment with EA at $\mathrm{T}_{\mathrm{smin}}=115^{\circ} \mathrm{C}$ was repeated by employing Biomass2. For sake of comparison, the results of the analyses on the extracted and nonextracted polymer fractions were reported in Table 3 together with those obtained from Biomass1 at $\mathrm{T}_{\mathrm{E}}=\mathrm{T}_{\mathrm{smin}}\left(100^{\circ} \mathrm{C}\right)$ and at $\mathrm{T}_{\mathrm{E}}=115^{\circ} \mathrm{C}$.

Table 3. Summary of recovered fractions $\left(f_{T O T}, f_{E}, f_{N E}\right)$, chemical composition and molecular weight of extracted and non-extracted PHA from Biomass1 and Biomass2 with EA.

\begin{tabular}{|c|c|c|c|c|c|c|c|c|c|c|}
\hline \multirow{2}{*}{ Sample } & \multicolumn{3}{|c|}{$\begin{array}{l}\text { Recovered Fractions } \\
\qquad(w t \%)\end{array}$} & \multicolumn{3}{|c|}{ Composition (3HB mol\%) } & \multicolumn{4}{|c|}{$M_{v}\left(\mathrm{~kg} \cdot \mathrm{mol}^{-1}\right)$} \\
\hline & $f_{\text {TOT }}$ & $f_{E}$ & $f_{N E}$ & R-PHA & E-PHA & NE-PHA & R-PHA & R-PHA $T_{E}=T_{s}$ & E-PHA & NE-PHA \\
\hline Biomass1 $\mathrm{T}_{\mathrm{E}}=100^{\circ} \mathrm{C}$ & 98 & 54 & 44 & 83 & 69 & 88 & 139 & 133 & 72 & 126 \\
\hline Biomass $1 \mathrm{~T}_{\mathrm{E}}=115^{\circ} \mathrm{C}$ & 94 & 71 & 23 & 83 & 78 & 85 & 139 & 104 & 62 & 98 \\
\hline Biomass2 $\mathrm{T}_{\mathrm{E}}=115^{\circ} \mathrm{C}$ & 92 & 66 & 25 & 89 & 84 & 92 & 405 & 333 & 236 & 358 \\
\hline
\end{tabular}

As for Biomass1, the extraction from Biomass2 brought about the preferential solubilization of polymer fractions with $3 \mathrm{HB}$ content and $M_{v}$ lower than those of the reference sample. Moreover, an overall reduction of PHA $M_{v}$ took place in all the experiments.

A slightly higher solubility of 3HV-rich PHA and a decrease of $M_{v}$ of the extracted PHA was also observed by Samorì et al. in extraction experiments carried out by dimethyl carbonate (DMC) [47]. Moreover, it can be observed that at $\mathrm{T}_{\mathrm{E}}=115^{\circ} \mathrm{C}, f_{E}$ is lower the higher is the molecular weight of the pristine polymer in the biomass.

To the best knowledge of authors, the EA or other linear esters as PHA extraction solvents are poorly reported in the literature and no examples are available on EEs use as a solvent for the extraction of PHA derived from MMC. As for the PHA solubility in EA, Terada and Marchessault [48], by a semi-empirical approach based on solubility parameters, found that EA could solubilize amorphous $\mathrm{P}(3 \mathrm{HB})$ but not the polymer in solvent inaccessible crystalline regions. In general, it was observed that short-chain length PHAs, such as $\mathrm{P}(3 \mathrm{HB})$ homopolymer and $\mathrm{P} 3 \mathrm{HB}-\mathrm{co}-3 \mathrm{HV}$ copolymers, show lower solubility in non-halogenated hydrocarbon than medium-chain and long-chain-length polymers (mcl- 
PHA, lcl-PHA). In fact, EA has been successfully used as a solvent for the extraction from biomass of poly(3-hydroxybutyrate-co-3-hydroxyhexanoate) (P3HB-co-3HHx) containing high levels of $\mathrm{HHx}(>15 \mathrm{~mol} \%)$, giving a recovery yield of $99 \mathrm{wt} \%$ at $100{ }^{\circ} \mathrm{C}$ [28]. More in detail, a comparison between EA and butyl acetate, both applied for extraction from Ralstonia eutropha pure cells at $76 \mathrm{wt} \%$ of PHA content, indicated EA as the best performing for the recovery yield and that both of them were excellent in the final PHA purity. The same study indicated the necessity to perform the extraction on dried biomass, since the presence of water had a double effect on ester hydrolysis and the reduction of the solvating power. The same extraction by EA of $\mathrm{P}(3 \mathrm{HB}-\mathrm{co}-3 \mathrm{HHx})$ obtained from Aeromonas hydrophila $4 \mathrm{AK} 4$ has also been employed in industrial-scale production [49]. Conversely, Samori et al. [29] found a very low recovery ( $5 \mathrm{wt} \%)$ in the extraction of P3HB with ethyl acetate at $80^{\circ} \mathrm{C}$. Similarly, the Soxhlet extraction of $\mathrm{P}(3 \mathrm{HB})$ with EA has been reported to give a low recovery yield of $29 \mathrm{wt} \%$ [50]. However, the unexpected high solubility of high molecular weight PHB $\left(1 \times 10^{6} \mathrm{~g} \mathrm{~mol}^{-1}\right)$ in EA at temperatures below the boiling point was found by Aramvash et al. [51], who extracted the polymer from wet biomass with surprisingly high yields. Additionally, Gahlawat and Kumar Soni [52] found a good recovery yield in the extraction of $\mathrm{P}(3 \mathrm{HB}-\mathrm{co}-3 \mathrm{HV})$ at high $3 \mathrm{HV}$ content $(24.6 \% \mathrm{~mol} / \mathrm{mol})$ with $\mathrm{EA}$, on a pure single strain (Cupriavidus necator DSM 545). This study reported a recovery yield of $96 \mathrm{wt} \%$, and a purity of $93 \%$ by using EA at $100{ }^{\circ} \mathrm{C}$. They also observed that the extraction brought about a reduction of the pristine molecular weight of PHA in the biomass, from 150.5 to $125 \mathrm{~kg} \mathrm{~mol}^{-1}$.

However, the different results reported in the literature could depend on different aspects such as the PHA composition and the culture type. With specific reference to the latter, it has been generally observed that PHA extraction from MMCs is more challenging in comparison to single strain cultures [17].

A possible extraction of PHA at a temperature above the boiling point with nonsolvent or poor-solvent at room temperature, among which EEs are included, has been reported in patents but without indication on yields and possible effects on the composition, chemical or physical-chemical properties of the extracted polymer [21,53].

\subsection{FT-IR and 1H-NMR Analysis}

In order to investigate the cause of the molecular weight reduction of E-PHA, mainly occurring at the higher extraction temperatures, the FT-IR spectra of the extracted samples were compared to those of relevant R-PHAs. In Figure 5, the spectra of R-PHA1 and E-PHA1 extracted at $100{ }^{\circ} \mathrm{C}$ as well as $150^{\circ} \mathrm{C}$ are reported as an example.

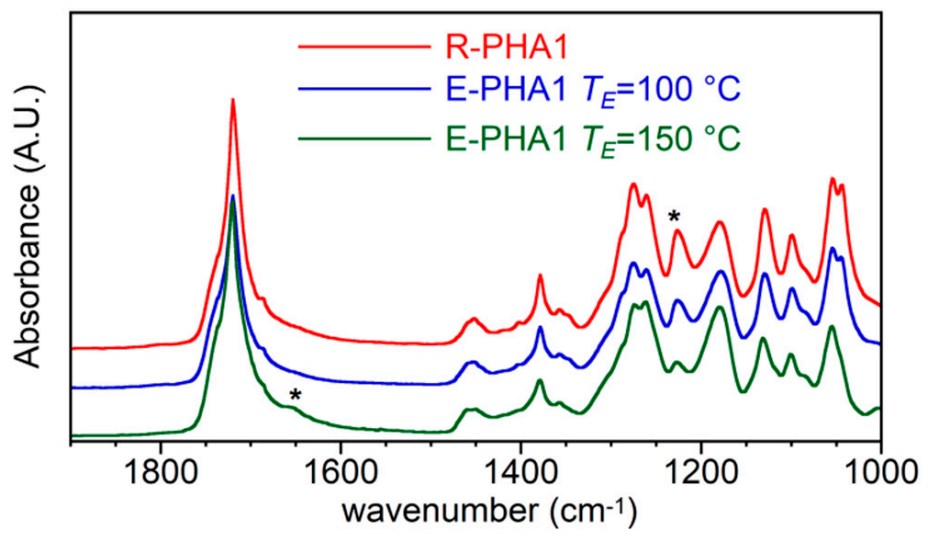

Figure 5. FTIR spectra of R-PHA1 and E-PHA1 extracted with AE at $100{ }^{\circ} \mathrm{C}$ and $150{ }^{\circ} \mathrm{C}$.

No marked differences can be observed comparing the spectra of R-PHA1 and EPHA1 extracted at $100^{\circ} \mathrm{C}$, which showed the expected bands of $\mathrm{P}(3 \mathrm{HB}-\mathrm{co}-3 \mathrm{HV})$ copolymer, where the strong band at $1223 \mathrm{~cm}^{-1}$, due to $\mathrm{C}-\mathrm{O}-\mathrm{C}$ stretching regular chain conformation, is indicative of high crystallinity. On the other hand, the sample extracted at $150{ }^{\circ} \mathrm{C}$ showed 
a clear hump at $1660 \mathrm{~cm}^{-1}$, which can be attributed to a $\mathrm{C}=\mathrm{C}$ stretching, reported as a possible degradation product located at one terminal of the polymer chain [54], and a drastic decrease of the band at $1223 \mathrm{~cm}^{-1}$, which was a sign of the predominant amorphous feature of the polymer.

Then, a further study on the degradation process and the macromolecule scission mechanism was carried out by analyzing the sample extracted at $150{ }^{\circ} \mathrm{C}$ by $1 \mathrm{H}-\mathrm{NMR}$ spectroscopy. The spectrum and the assignments of the signals are reported in Figure 6.

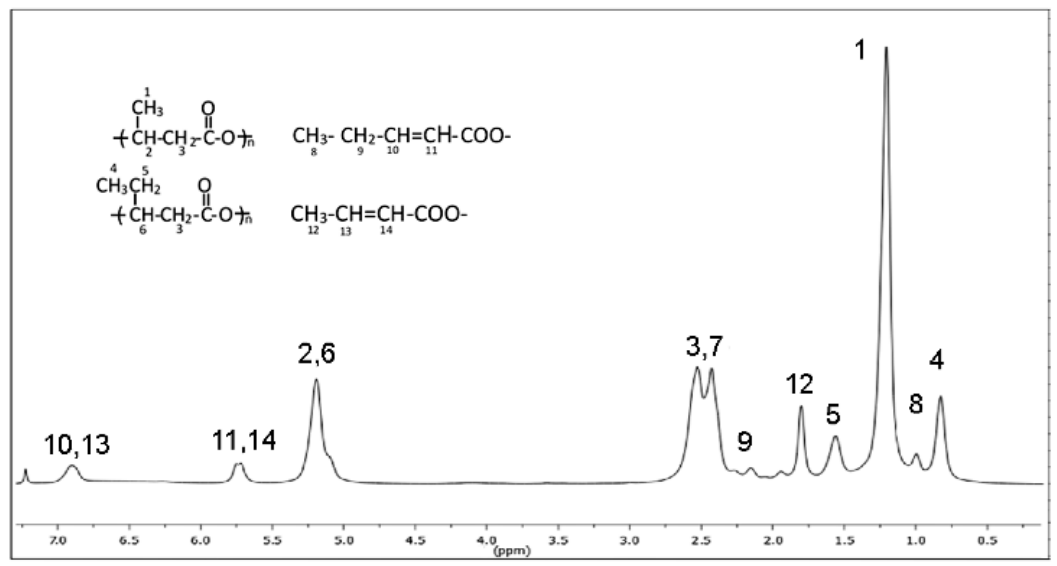

Figure 6. $1 \mathrm{HNMR}$ of PHA extracted at $150{ }^{\circ} \mathrm{C}$ for $1 \mathrm{~h}$ and assignments of the peaks.

Besides the typical features of the copolymer $\mathrm{P}(3 \mathrm{HB}-\mathrm{co}-3 \mathrm{HV})$, the spectrum showed new signals assigned to unsaturated crotonate terminal groups. They were due to the random chain scission occurring through a $\beta$-elimination and $\alpha$-deprotonation mechanism, according to reported studies on thermal degradation of PHA above the melting temperature $[46,55]$. Then, the decrease of total polymer recovery (E-PHA1 plus NE-PHA1) recorded at temperatures higher than $125^{\circ} \mathrm{C}$ (Figure 4A) can be attributed to the scission of the terminal repeating units which produced volatile low molecular weight product. The absence of peaks of acetate or ethoxy protons lets us exclude that molecular weight reduction was caused by possible transesterification between EA and PHA favored by high temperature. The absence of the $\mathrm{C}=\mathrm{C}$ stretching absorption in the sample extracted at $\mathrm{T}_{\mathrm{E}}<130^{\circ} \mathrm{C}$ was due to the low concentration of terminal crotonic groups because of the higher polymer molecular weight. However, it can be presumed that the chain scission follows the same reaction mechanism also at $\mathrm{T}_{\mathrm{E}}<150{ }^{\circ} \mathrm{C}$.

\section{Conclusions}

The present study showed that the extraction of $\mathrm{P}(3 \mathrm{HB}-\mathrm{co}-3 \mathrm{HV})$ copolymers from the biomass by the selected three ethylic esters brings about a polymer with high purity and that the extracted polymer composition, recovery yield and molecular weight depend on the extraction conditions as well as on the MW of pristine polymer in the biomass. The preliminary dissolution tests carried out on reference PHA, extracted from biomass with chloroform, showed that:

- $\quad$ ethyl acetate is the best solvent because it dissolves the copolymer at a temperature lower than ethyl propionate and ethyl butyrate;

- by increasing the temperature from $100{ }^{\circ} \mathrm{C}$ to $150{ }^{\circ} \mathrm{C}$, the PHA dissolved in ethyl acetate underwent a progressive reduction of its molecular weight.

The results of the extraction of PHA from biomasses showed that:

- $\quad$ the higher the molecular weight of the polymer in the biomass, the lower the recovery yield;

- $\quad$ at the minimum dissolution temperature, ethyl acetate gave recovery yields higher than the other ethylic esters, and that it preferentially extracts the copolymer fraction richer in $3 \mathrm{HV}$ comonomer and with the lower molecular weight; 
- by increasing the extraction temperature from $100{ }^{\circ} \mathrm{C}$ to $130{ }^{\circ} \mathrm{C}$, the recovery yield increased from about $50 \mathrm{wt} \%$ to $80 \mathrm{wt} \%$ and the composition of the extracted polymer approached that of the reference sample;

- by increasing the extraction temperature up to $150{ }^{\circ} \mathrm{C}$, a progressive reduction of molecular weight of the extracted polymer and of the polymer fraction remaining in the biomass occurred;

- $\quad$ the purity of the samples extracted with ethyl acetate was always very high, between 90 and $97 \mathrm{wt} \%$, without the need for further purification by anti-solvent precipitation.

FTIR and 1H-NMR analyses, carried out on a PHA sample extracted by the harshest condition $\left(150{ }^{\circ} \mathrm{C}\right)$, showed that the chain scission occurred with the formation of crotonic groups at the polymer ends, through the same mechanism of the PHA thermal decomposition above its melting point.

In conclusion, the use of ethylic esters of VFA could be an attractive method to extract PHA when the use of safe and non-toxic solvents is mandatory, particularly in the case where their synthesis is included in the virtuous cycle of biorefinery. Moreover, the results highlighted that it is possible to choose the proper extraction condition to maximize the recovery yield at the expense of polymer fractionation and degradation at high temperatures or use mild conditions to maintain the original properties of polymer in the biomass.

Author Contributions: Conceptualization, A.M. and S.A.; methodology, A.M., S.A., L.L. and F.V.; formal analysis, A.M., M.M. and F.V.; investigation, S.A., A.M., L.L. and F.S.; data curation, A.M., S.A., L.L.; writing—original draft preparation, A.M.; writing—review and editing, S.A., L.L., F.V. and M.M.; supervision, A.M. and M.M.; project administration, M.M.; funding acquisition, M.M. All authors have read and agreed to the published version of the manuscript.

Funding: This research was funded by the Resources from URban BIo-waSte-RES URBIS (Grant Agreement 730349) project in the European Horizon2020 (Call CIRC-05-2016) program.

Acknowledgments: The authors gratefully acknowledge Guseppe Bifolchi for performing a part of the experimental tests in the framework of his MSc thesis.

Conflicts of Interest: The authors declare no conflict of interest.

\begin{abstract}
Abbreviations
3HB: 3-hydroxybutyrate comonomeric unit; 3HV, 3-hydroxyvalerate comonomeric unit; EA, ethyl acetate; EB, ethyl butyrate; EEs, ethylic esters of VFA; EP, ethyl propionate; E-PHA, extracted PHA; $f_{E}$, extracted PHA fraction; $f_{N E}$, non-extracted PHA fraction; GC, gas chromatography; MMC, Mixed microbial culture; $M_{v}$, viscosity average molecular weight; $\mathrm{MW}$, molecular weight; NE-PHA, non-extracted PHA; OFMSW, organic fraction of municipal solid waste; PHA, Poly(hydroxyalkanoate); P(3HB), Poly(3-hydroxybutyrate) homopolymer; P(3HB-co-3HV), Poly(3hydroxybutyrate-co-3-hydroxyvalerate) copolymer; R-PHA, reference PHA extracted with chloroform; $\mathrm{SS}$, sewage sludge; $\mathrm{T}_{\mathrm{E}}$, extraction temperature; $\mathrm{T}_{\mathrm{S}}$, solubilisation temperature; $\mathrm{T}_{\mathrm{smin}}$, minimum solubilisation temperature; VFA, volatile fatty acid; WAS, waste activated sludge.
\end{abstract}

\title{
References
}

1. Andreasi Bassi, S.; Boldrin, A.; Frenna, G.; Astrup, T.F. An Environmental and Economic Assessment of Bioplastic from Urban Biowaste. The Example of Polyhydroxyalkanoate. Bioresour. Technol. 2021, 327, 124813. [CrossRef]

2. Vermeer, C.M.; Tamis, J.; Jonkers, H.M.; Kleerebezem, R. From Waste to Self-Healing Concrete: A Proof-of-Concept of a New Application for Polyhydroxyalkanoate. Resour. Conserv. Recy. 2021, 164, 105206. [CrossRef]

3. Keskin, G.; Klzll, G.; Bechelany, M.; Pochat-Bohatier, C.; Öner, M. Potential of Polyhydroxyalkanoate (PHA) Polymers Family as Substitutes of Petroleum Based Polymers for Packaging Applications and Solutions Brought by Their Composites to Form Barrier Materials. Pure Appl. Chem. 2017, 89, 1841-1848. [CrossRef]

4. Kulkarni, S.O.; Kanekar, P.P.; Jog, J.P.; Patil, P.A.; Nilegaonkar, S.S.; Sarnaik, S.S.; Kshirsagar, P.R. Characterisation of Copolymer, Poly (Hydroxybutyrate-Co-Hydroxyvalerate) (PHB-Co-PHV) Produced by Halomonas Campisalis (MCM B-1027), Its Biodegradability and Potential Application. Bioresour. Technol. 2011, 102, 6625-6628. [CrossRef] [PubMed] 
5. Philip, S.; Keshavarz, T.; Roy, I. Polyhydroxyalkanoates: Biodegradable Polymers with a Range of Applications. J. Chem. Technol. Biotechnol. 2007, 82, 233-247. [CrossRef]

6. Valentino, F.; Gottardo, M.; Micolucci, F.; Pavan, P.; Bolzonella, D.; Rossetti, S.; Majone, M. Organic Fraction of Municipal Solid Waste Recovery by Conversion into Added-Value Polyhydroxyalkanoates and Biogas. ACS Sustain. Chem. Eng. 2018, 6, 16375-16385. [CrossRef]

7. Madkour, M.H.; Heinrich, D.; Alghamdi, M.A.; Shabbaj, I.I.; Steinbüchel, A. PHA Recovery from Biomass. Biomacromolecules 2013, 14, 2963-2972. [CrossRef]

8. Rodriguez-Perez, S.; Serrano, A.; Pantión, A.A.; Alonso-Fariñas, B. Challenges of Scaling-up PHA Production from Waste Streams. A Review. J. Environ. Manag. 2018, 205, 215-230. [CrossRef]

9. Koller, M.; Braunegg, G. Advanced Approaches to Produce Polyhydroxyalkanoate (PHA) Biopolyesters in a Sustainable and Economic Fashion. EuroBiotech J. 2018, 2, 89-103. [CrossRef]

10. Valentino, F.; Moretto, G.; Lorini, L.; Bolzonella, D.; Pavan, P.; Majone, M. Pilot-Scale Polyhydroxyalkanoate Production from Combined Treatment of Organic Fraction of Municipal Solid Waste and Sewage Sludge. Ind. Eng. Chem. Res. 2019, 58, 12149-12158. [CrossRef]

11. Moretto, G.; Russo, I.; Bolzonella, D.; Pavan, P.; Majone, M.; Valentino, F. An Urban Biorefinery for Food Waste and Biological Sludge Conversion into Polyhydroxyalkanoates and Biogas. Water Res. 2020, 170, 115371. [CrossRef]

12. Werker, A.; Bengtsson, S.; Korving, L.; Hjort, M.; Anterrieu, S.; Alexandersson, T.; Johansson, P.; Karlsson, A.; Karabegovic, L.; Magnusson, P. Consistent Production of high quality PHa using activated sludge harvested from full scale municipal wastewaterreatment- PHARIO. Water Sci. Technol. 2018, 11, 2256-2269. [CrossRef]

13. Valentino, F.; Morgan-Sagastume, F.; Campanari, S.; Villano, M.; Werker, A.; Majone, M. Carbon Recovery from Wastewater through Bioconversion into Biodegradable Polymers. New Biotechnol. 2017, 37, 9-23. [CrossRef]

14. Kourmentza, C.; Plácido, J.; Venetsaneas, N.; Burniol-Figols, A.; Varrone, C.; Gavala, H.N.; Reis, M.A.M. Recent Advances and Challenges towards Sustainable Polyhydroxyalkanoate (PHA) Production. Bioengineering 2017, 4, 55. [CrossRef] [PubMed]

15. Reis, M.; Albuquerque, M.; Villano, M.; Majone, M. Mixed culture processes for polyhydroxyalkanoate production from agro-industrial surplus/wastes as feedstocks. In Comprehensive Biotechnology; Fava, F., Agathos, S., Young, M., Eds.; Elsevier: Amsterdam, The Netherlands, 2011; pp. 669-683.

16. Majone, M.; Chronopoulou, L.; Lorini, L.; Martinelli, A.; Palocci, C.; Rossetti, S.; Valentino, F.; Villano, M. PHA Copolymers from Microbial Mixed Coltures: Synthesis, Extraction and Related Properties. In Current Advantages in Biopolymer Processing and Characterization; Koller, M., Ed.; Nova Science Publisher: New York, NY, USA, 2017; pp. 223-277.

17. Pagliano, G.; Galletti, P.; Samorì, C.; Zaghini, A.; Torri, C. Recovery of Polyhydroxyalkanoates From Single and Mixed Microbial Cultures: A Review. Front. Bioeng. Biotechnol. 2021, 9, 624021. [CrossRef] [PubMed]

18. Pérez-Rivero, C.; López-Gómez, J.P.; Roy, I. A Sustainable Approach for the Downstream Processing of Bacterial Polyhydroxyalkanoates: State-of-the-Art and Latest Developments. Biochem. Eng. J. 2019, 150, 107283. [CrossRef]

19. Koller, M. Established and Advanced Approaches for Recovery of Microbial Polyhydroxyalkanoate (PHA) Biopolyesters from Surrounding Microbial Biomass. EuroBiotech J. 2020, 4, 113-126. [CrossRef]

20. Kurdikar, D.L.; Strauser, F.E.; Solodar, A.J.; Paster, M.D.; Asrar, J. Methods of PHA Extraction and Recovery Using NonHalogenated Solvents. U.S. Patent US6043063A, 14 April 1998.

21. Kurdikar, D.L.; Strauser, F.E.; Solodar, A.J.; Paster, M.D. High Temperature PHA Extraction Using PHA-Poor. Solvents. Patent WO/1998/046783, 22 October 1998.

22. Macagnan, K.L.; Alves, M.I.; Moreira, A. Approaches for Enhancing Extraction of Bacterial Polyhydroxyalkanoates for Industrial Applications. In Biotechnological Applications of Polyhydroxyalkanoates; Springer: Singapore, 2019.

23. Dubey, S.; Bharmoria, P.; Gehlot, P.S.; Agrawal, V.; Kumar, A.; Mishra, S. 1-Ethyl-3-methylimidazolium Diethylphosphate Based Extraction of Bioplastic "Polyhydroxyalkanoates" from Bacteria: Green and Sustainable Approach. ACS Sustain. Chem. Eng. 2018, 6, 766-773. [CrossRef]

24. Jacquel, N.; Lo, C.W.; Wei, Y.H.; Wu, H.S.; Wang, S.S. Isolation and Purification of Bacterial Poly(3-Hydroxyalkanoates). Biochem. Eng. J. 2008, 39, 15-27. [CrossRef]

25. Jiang, G.; Johnston, B.; Townrow, D.E.; Radecka, I.; Radecka, I.; Chaber, P.; Adamus, Z.; Kowalczuk, M. Biomass Extraction Using Non-Chlorinated Solvents for Biocompatibility Improvement of Polyhydroxyalkanoates. Polymers 2018, $10,731$. [CrossRef] [PubMed]

26. Rosengart, A.; Cesário, M.T.; de Almeida, M.T.; Raposo, R.S.; Espert, A.; Díazde Apodaca, E.; da Fonseca, M.M. Efficient P(3HB) extraction from Burkholderia sacchari cells using non-chlorinated solvents. Biochem. Eng. J. 2015, 103, 39-46. [CrossRef]

27. Yabueng, N.; Napathorn, S.C. Toward non-toxic and simple recovery process of poly (3-hydroxybutyrate) using the green solvent 1, 3-dioxolane. Process Biochem. 2018, 69, 197-207. [CrossRef]

28. Riedel, S.L.; Brigham, C.J.; Budde, C.F.; Bader, J.; Rha, C.; Stahl, U.; Sinskey, A.J. Recovery of Poly(3-Hydroxybutyrate-Co-3Hydroxyhexanoate) from Ralstonia eutropha Cultures with Non-Halogenated Solvents. Biotechnol. Bioeng. 2013, 110, 461-470. [CrossRef] [PubMed]

29. Samorì, C.; Basaglia, M.; Casella, S.; Favaro, L.; Galletti, P.; Giorgini, L.; Marchi, D.; Mazzocchetti, L.; Torri, C.; Tagliavini, E. Dimethyl Carbonate and Switchable Anionic Surfactants: Two Effective Tools for the Extraction of Polyhydroxyalkanoates from Microbial Biomass. Green Chem. 2015, 17, 1047-1056. [CrossRef] 
30. Fiorese, M.L.; Freitas, F.; Pais, J.; Ramos, A.M.; de Aragão, G.M.F.; Reis, M.A.M. Recovery of polyhydroxybutyrate (PHB) from Cupriavidus necator biomass by solvent extraction with 1,2-propylene carbonate. Eng. Life Sci. 2009, 9, 454-461. [CrossRef]

31. de Souza Reis, G.A.; Michels, M.H.A.; Fajardo, G.L.; Lamot, I.; de Best, J.H. Optimization of Green Extraction and Purification of PHA Produced by Mixed Microbial Cultures from Sludge. Water 2020, 12, 1185. [CrossRef]

32. Mongili, B.; Abdel Azim, A.; Fraterrigo Garofalo, S.; Batuecas, E.; Re, A.; Bocchini, S.; Fino, D. Novel insights in dimethyl carbonate-based extraction of polyhydroxybutyrate (PHB). Biotechnol. Biofuels 2021, 14, 13. [CrossRef]

33. Koller, M.; Bona, R.; Chiellini, E.; Braunegg, G. Extraction of short-chain-length poly-[(R)-hydroxyalkanoates] (scl-PHA) by the "anti-solvent" acetone under elevated temperature and pressure. Biotechnol. Lett. 2013, 35, 1023-1028. [CrossRef]

34. Chan, C.M.; Johansson, P.; Magnusson, P.; Vandi, L.J.; Arcos-Hernandez, M.; Halley, P.; Laycock, B.; Pratt, S.; Werker, A. Mixed culture polyhydroxyalkanoate-rich biomass assessment and quality control using thermogravimetric measurement methods. Polym. Degrad. Stab. 2017, 144, 110-120. [CrossRef]

35. Nonato, R.; Mantelatto, P.; Rossell, C. Integrated production of biodegradable plastic, sugar and ethanol. Appl. Microbiol. Biotechnol. 2001, 57, 1-5. [CrossRef]

36. Righi, S.; Baioli, F.; Samorì, C.; Galletti, P.; Tagliavini, E.; Stramigioli, C.; Tugnoli, A.; Fantke, P. A life cycle assessment of poly-hydroxybutyrate extraction from microbial biomass using dimethyl carbonate. J. Clean. Prod. 2017, 168, 692-707. [CrossRef]

37. Di Bitonto, L.; Menegatti, S.; Pastore, C. Process Intensification for the Production of the Ethyl Esters of Volatile Fatty Acids Using Aluminium Chloride Hexahydrate as a Catalyst. J. Clean. Prod. 2019, 239, 118122. [CrossRef]

38. Prat, D.; Hayler, J.; Wells, A. A Survey of Solvent Selection Guides. Green Chem. 2014, 16, 4546-4551. [CrossRef]

39. Prat, D.; Wells, A.; Hayler, J.; Sneddon, H.; McElroy, C.R.; Abou-Shehadad, S. Selection Guide of Classical- and Less ClassicalSolvents. Green Chem. 2016, 18, 288-296. [CrossRef]

40. Lorini, L.; Martinelli, A.; Pavan, P.; Majone, M.; Valentino, F. Downstream Processing and Characterization of Polyhydroxyalkanoates (PHAs) Produced by Mixed Microbial Culture (MMC) and Organic Urban Waste as Substrate. Biomass Convers. Biorefinery 2020, 11, 693-703. [CrossRef]

41. Braunegg, G.; Sonnleitner, B.; Lafferty, R. Rapid Gas-Chromatographic Method for Determination of Poly-Beta-Hydroxybutyric Acid in Microbial Biomass. Eur. J. Appl. Microbiol. Biotechnol. 1978, 6, 29-37. [CrossRef]

42. Marchessault, R.H.; Okamura, K.; Su, C.J. Physical Properties of Poly (3-Hydroxy Butyrate). II. Conformational Aspects in Solution. Macromolecules 1970, 3, 735-740. [CrossRef]

43. Hu, S.; McDonald, A.G.; Coats, E.R. Characterization of Polyhydroxybutyrate Biosynthesized from Crude Glycerol Waste Using Mixed Microbial Consortia. J. Appl. Polym. Sci. 2013, 129, 1314-1321. [CrossRef]

44. Lorini, L.; Martinelli, A.; Capuani, C.; Frison, N.; Reis, M.A.M.; Sommer Ferreira, B.; Villano, M.; Majone, M.; Valentino, F. Characterization of Polyhydroxyalkanoates Produced at Pilot Scale from Different Organic Wastes. Front. Bioeng. Biotechnol. 2021, 9, 628719. [CrossRef] [PubMed]

45. Kopinke, F.-D.; Remmler, M.; Mackenzie, K. Thermal decomposition of biodegradable polyesters-I: Poly ( $\beta$-hydroxybutyric acid). Polym. Degrad. Stabil. 1996, 52, 25-38. [CrossRef]

46. Xiang, H.; Wen, X.; Miu, X.; Li, Y.; Zhou, Z.; Zhu, M. Thermal depolymerization mechanisms of poly(3-hydroxybutyrate-co-3hydroxyvalerate). Prog. Nat. Sci. 2016, 26, 58-64. [CrossRef]

47. Samorì, C.; Abbondanzi, F.; Galletti, P.; Giorgini, L.; Mazzocchetti, L.; Torri, C.; Tagliavini, E. Extraction of Polyhydroxyalkanoates from Mixed Microbial Cultures: Impact on Polymer Quality and Recovery. Bioresour. Technol. 2015, 189, 195-202. [CrossRef]

48. Terada, M.; Marchessault, R.H. Determination of Solubility Parameters for Poly(3-Hydroxyalkanoates). Int. J. Biol. Macromol. 1999, 25, 207-215. [CrossRef]

49. Chen, G.; Zhang, G.; Park, S.; Lee, L. Industrial Scale Production of Poly(3-Hydroxybutyrate-Co-3-Hydroxyhexanoate). Appl. Microbiol. Biotechnol. 2001, 57, 50-55. [CrossRef] [PubMed]

50. Manangan, T.; Shawaphun, S. Quantitative Extraction and Determination of Polyhydroxyalkanoate Accumulated in Alcaligenes Latus Dry Cells. Sci. Asia 2010, 36, 199-203. [CrossRef]

51. Aramvash, A.; Gholami-Banadkuki, N.; Moazzeni-Zavareh, F.; Hajizadeh-Turchi, S. An Environmentally Friendly and Efficient Method for Extraction of PHB Biopolymer with Non-Halogenated Solvents. J. Microbiol. Biotechnol. 2015, 25, 1936-1943. [CrossRef]

52. Gahlawat, G.; Soni, S.K. Study on Sustainable Recovery and Extraction of Polyhydroxyalkanoates (PHAs) Produced by Cupriavidus Necator Using Waste Glycerol for Medical Applications. Chem. Biochem. Eng. Q. 2019, 33, 99-110. [CrossRef]

53. Werker, A.G.; Johansson, P.S.T.; Magnusson, O.G. Process for the Extraction of Polyhydroxyalkanoates from Biomass. U.S. Patent US20150368393A1, 24 December 2015.

54. Grassie, N.; Murray, E.J.; Holmes, P.A. The Thermal Degradation of Poly(-(d)- $\beta$-Hydroxybutyric Acid): Part 1 -Identification and Quantitative Analysis of Products. Polym. Degrad. Stab. 1984, 6, 47-61. [CrossRef]

55. Nguyen, S.; Yu, G.; Marchessault, R.H. Thermal Degradation of Poly(3-Hydroxyalkanoates): Preparation of Well-Defined Oligomers. Biomacromolecules 2002, 3, 219-224. [CrossRef] 